\title{
Understanding the piezoelectric properties in potassium-sodium niobate- based lead-free piezoceramics: Interrelationship between intrinsic and extrinsic factors
}

Fernando Rubio-Marcos ${ }^{\dagger, \xi, *}$, José F. Fernandez, Diego A. Ochoa", José E. Garcíall, Rocio E. Rojas-Hernandez ${ }^{\dagger}$, Miriam Castro $\neq$, Leandro Ramajo $\neq, \&$, *

${ }^{\dagger}$ Electroceramic Department, Instituto de Cerámica y Vidrio, CSIC, Kelsen 5, 28049, Madrid, Spain.

"Department of Physics, Universitat Politècnica de Catalunya - BarcelonaTech, Jordi Girona 1-3, 08034 Barcelona, Spain.

‡ Institute of Research in Materials Science and Technology (INTEMA) (CONICET - University of Mar del Plata), J. B. Justo 4302 (B7608FDQ) Mar del Plata, Argentina.

*Authors to whom correspondence should be addressed. F. R-M: Phone: +34 917355840 Fax: +34 917355843 . Email: frmarcos@icv.csic.es and L. R. Phone: +54-223-4816600 (ext. 238) e-mail: $\underline{\text { lramajo@fi.mdp.edu.ar }}$

${ }^{\S}$ Author Contributions: F. Rubio-Marcos and L. Ramajo contributed equally.

\begin{abstract}
Lead zirconate titanate (PZT) based ceramics are currently enjoying a wide use in piezoelectric devices despite lead toxicity. Due to growing environmental concerns, the attention on piezoelectric ceramics has been moving to lead-free materials, in particular to $(\mathrm{K}, \mathrm{Na}) \mathrm{NbO}_{3}$-based ceramics. Here we report a systematic evaluation of the effects of the compositional modifications on $\left[\left(\mathrm{K}_{0.44} \mathrm{Na}_{0.52} \mathrm{Li}_{0.04}\right)\left[\left(\mathrm{Nb}_{0.86} \mathrm{Ta}_{0.10} \mathrm{Sb}_{0.04}\right)_{1-\mathrm{x}} \mathrm{Zr}_{5 \mathrm{x} / 4}\right] \mathrm{O}_{3} \quad\right.$ lead-free piezoceramics. We show that an interrelationship between the intrinsic and extrinsic factors is the linchpin for the development of good piezoelectric properties. Hence, the stabilization of the tetragonal symmetry on the orthorhombic-tetragonal polymorphic phase boundary facilities the poling process of the system, thereby enhancing the piezoelectric response. Additionally, the microstructure appears to be related to the piezoelectric properties; i.e., the improved piezoelectric properties correlate to the increase in grain size. The results of this work could help to understand the origin of piezoelectricity in potassium-sodium niobate-based ceramics.
\end{abstract}

KEYWORDS: Lead-free materials; Potassium-Sodium Niobate phase; Piezoelectric ceramics 
This is the post-print (i.e. final draft post-refereeing) of the publication.

The final publication is available at Elsevier via http://dx.doi.org/ 10.1016/j.jeurceramsoc.2017.04.045

\section{Introduction}

Lead titanate-zirconate (PZT) ceramics are the most widely used piezoelectric materials. However, legal restrictions on the use of lead in electrical and electronic devices have led to greater efforts being made to develop lead-free alternatives to PZT-based materials [1-6]. Hence, many researchers have attempted to present materials capable of replacing lead-based ceramics [4-26]. Among these attempts, potassium-sodium niobate, $\mathrm{K}_{x} \mathrm{Na}_{1-\mathrm{x}} \mathrm{NbO}_{3}(\mathrm{KNN})$, ceramics have become one of the most investigated systems over the past ten years [10-26], ever since an exceptionally high piezoelectric constant $\left(d_{33}\right)$ of $\sim 400$ pC $\mathrm{N}^{-1}$ was reported by Saito et al. in 2004 [12]. This findings were based on chemical modifications by complex simultaneous substitutions into the A ( $\mathrm{Li})$ and $\mathrm{B}(\mathrm{Ta}$ and $\mathrm{Sb})$ sites of the perovskite crystal lattice for a composition close to the morphotropic phase boundary (MPB) of the KNN system. In addition to these chemical modifications, a novel processing route for producing textured polycrystals has been carried out in this work. However, the inhomogeneous distribution of $\mathrm{Nb}$, Ta and $\mathrm{Sb}$ on the B-site of the perovskite lattice is rather difficult to avoid because of the phase segregation of end members over a wide temperature interval [27]. Furthermore, apparent compositional segregation is evidenced in KNN ceramics annealed for a long time [10,27-29].

More recently, Zhu's group chemically designed a series of KNN-based ternary ceramic systems that effectively enhance the piezoelectric properties by tuning phase boundaries $[24,30,31]$. In this context, the polymorphic phase boundary (PPB) in lead-free piezoelectric materials, and particularly in KNN-based compositions, has attracted significant interest because of the unique properties found in their vicinity. However, in order to harness the full potential of these materials as micro-nanoscale functional entities, it is essential to achieve a reliable and precise control of the macroscopic response in the PPB. The enhancement of the macroscopic properties in a PPB is due to two contributions, which are known as intrinsic and extrinsic contributions. On the one hand, the intrinsic contribution is related to the linear lattice distortion, and is associated with the change in the polarization of the unit cell. As a 
This is the post-print (i.e. final draft post-refereeing) of the publication.

The final publication is available at Elsevier via http://dx.doi.org/ 10.1016/j.jeurceramsoc.2017.04.045

result of the phase coexistence, the polarization rotation enhances at the PPB region, thereby improving the piezoelectric properties. Moreover, the property enhancement at PPB has been reported as a consequence of an electric field-induced phase transition; i.e. a polarization extension phenomenon [32]. Thus, PPB is a region where material response is apparently enhanced owing to polarization rotation and polarization extension. On the other hand, the extrinsic contribution is easily defined as all responses different from the intrinsic one. Ochoa et. al. [33] have recently reported that, in addition to the intrinsic contribution, the extrinsic contribution (domain wall contribution) also maximizes in a PPB region. Thus, the extrinsic contribution is also responsible for improving the functional properties at the PPB [33]. Despite the progress achieved recently, a fundamental question nevertheless arises: What is the balance between the intrinsic and extrinsic contribution within a PPB? An attempt to answer this question is provided in this work.

Compositional engineering by doping is a classic approach in the field of piezoelectric materials to modify the structure and microstructure of materials, and therefore to tailor the piezoelectric response. Many aliovalent compositional modifications to KNN-based system have been studied, either with higher valence substitutions (donors) or with lower valence ions (acceptors) [24,34-38]. From this perspective, the $(\mathrm{K}, \mathrm{Na}) \mathrm{NbO}_{3}-\mathrm{LiTaO}_{3}-\mathrm{LiSbO}_{3}$ system was synthesized by replacing the B-sites with $\mathrm{Zr}^{4+}$ ions, thereby engendering an evolution of the polymorphic behaviour containing tetragonal $(T)$ and orthorhombic $(\boldsymbol{O})$ symmetries. Through this compositional design, we have found that a balance between the intrinsic and extrinsic contributions constitutes a linchpin in the development of good piezoelectric properties. The stabilization of the rich $T$ region into the PPB seems to be crucial for promoting the piezoelectric response. 
This is the post-print (i.e. final draft post-refereeing) of the publication.

The final publication is available at Elsevier via http://dx.doi.org/ 10.1016/j.jeurceramsoc.2017.04.045

\section{Experimental details}

\subsection{Preparation process}

Bearing in mind the ionic radii, the $\mathrm{Zr}^{4+}$ ion $\left(\mathrm{r}_{\mathrm{Zr}}{ }^{4+}: 0.72 \AA\right.$ for a coordination number $\left.\mathrm{CN}=6\right)$ [39] is in the size range of the B-site ions $\left(\mathrm{r}_{\mathrm{Nb}^{5+}}: 0.64 \AA, \mathrm{r}_{\mathrm{Ta}}{ }^{5+}: 0.64 \AA, \mathrm{rSb}^{5+}: 0.60 \AA\right.$ for $\left.\mathrm{CN}=6\right)$ [39] of the $(\mathrm{K}, \mathrm{Na}) \mathrm{NbO}_{3}-\mathrm{LiTaO}_{3}-\mathrm{LiSbO}_{3}$ system. Considering its valence, $\mathrm{Zr}^{4+}$ can act as acceptor dopant if introduced into the B-site, thereby modifying the properties of the system. Therefore, B-site deficient $\mathrm{Zr}^{4+} \quad$ doped $\quad\left(\mathrm{K}_{0.44} \mathrm{Na}_{0.52} \mathrm{Li}_{0.04}\right)\left(\mathrm{Nb}_{0.86} \mathrm{Ta}_{0.10} \mathrm{Sb}_{0.04}\right) \mathrm{O}_{3}$, with a global formula $\left(\mathrm{K}_{0.44} \mathrm{Na}_{0.52} \mathrm{Li}_{0.04}\right)\left[\left(\mathrm{Nb}_{0.86} \mathrm{Ta}_{0.10} \mathrm{Sb}_{0.04}\right)_{1-\mathrm{x}} \mathrm{Zr}_{5 \times / 4}\right] \mathrm{O}_{3}$, hereafter abbreviated as $\mathrm{KNL}-(\mathrm{NTS})_{1-\mathrm{x}} \mathrm{Zr}_{5 \times / 4}$, is selected as a PPB tunable system. Thus, $\mathrm{KNL}-(\mathrm{NTS})_{1-\mathrm{x}} \mathrm{Zr}_{5 \times / 4}$ ceramics with $x=0,0.005,0.01,0.03$, and 0.05 were prepared by conventional solid-state reaction from an adequate mixture of corresponding oxides and carbonates. $\mathrm{Na}_{2} \mathrm{CO}_{3}, \mathrm{Li}_{2} \mathrm{CO}_{3}$ (PANREAC, $\left.>99.5 \%\right), \mathrm{K}_{2} \mathrm{CO}_{3}\left(\mathrm{Merck}_{\bar{\gamma}}>99 \%\right), \mathrm{ZrO}_{2}, \mathrm{Nb}_{2} \mathrm{O}_{5}, \mathrm{Ta}_{2} \mathrm{O}_{5}$, and $\mathrm{Sb}_{2} \mathrm{O}_{5}$ (SIGMA-ALDRICH, > 99.9\%, >99\% and $>99.995 \%$, respectively) were used as starting raw materials and were individually milled in order to obtain an appropriate distribution of the particle size. Furthermore, the raw materials were dried at $200{ }^{\circ} \mathrm{C}$ for $4 \mathrm{~h}$ before use because of their hygroscopic nature [37]. Powders with different $\mathrm{ZrO}_{2}$ concentrations were weighted and ball-milled for $3 \mathrm{~h}$ in an ethanol medium in a high-energy laboratory ball-mill with Zirconia balls. Subsequently, the resulting powders were dried, sieved and calcined at $700{ }^{\circ} \mathrm{C}$ for $2 \mathrm{~h}$ at $3{ }^{\circ} \mathrm{C} / \mathrm{min}$ [40]. The calcined powders were ball-milled in a plastic jar with Zirconia grinding media for $3 \mathrm{~h}$ in ethanol and dried for $4 \mathrm{hrs}$ at $150^{\circ} \mathrm{C}$. Samples of $10 \mathrm{~mm}$ in diameter and $1 \mathrm{~mm}$ in thickness were uniaxially pressed at 200 MPa and sintered in air at $1125^{\circ} \mathrm{C}$ for $2 \mathrm{~h}$. Bulk densities of the samples were determined using the Archimedes method. 
This is the post-print (i.e. final draft post-refereeing) of the publication.

The final publication is available at Elsevier via http://dx.doi.org/ 10.1016/j.jeurceramsoc.2017.04.045

\subsection{X-ray diffraction (XRD) measurement}

XRD (X'Pert PRO Theta/2theta of Panalytical, PANalytical, The Netherlands) measurements were performed by applying $\mathrm{CuK}_{\alpha}(\lambda=0.154056 \mathrm{~nm})$ radiation on unpoled and poled sintered ceramics. The patterns were recorded over the angular range $10-70^{\circ}(2 \theta)$ with a step size of $0.0334^{\circ}$ and a time per step of 100 seconds. The working voltage and current were $40 \mathrm{kV}$ and $100 \mathrm{~mA}$, respectively. Structural refinement was performed using a tetragonal symmetry, (T, P4mm), and an orthorhombic symmetry, $(\mathrm{O}, \mathrm{Amm} 2)$. The cell parameters were then calculated by fitting the observed reflections with a leastsquares method using the Checkcell program [41]. The relative volume fractions were calculated by using the integrated intensities of the tetragonal (002) and (200) and orthorhombic (022) and (200) degenerate reflections, which obtained from the line profile analysis [11,42]. Peak positions were fitted assuming a Lorentz peak shape using the Peakoc software [43]. (More information about the phase volume fraction $v \mathrm{Z} \mathrm{Zr}$ content is shown in the Supplementary Information, section A). The intensities and the position of the maxima of the tetragonal (002) and (200) degenerate reflection were also used to calculate the relative percent of domain switching (extrinsic contribution) and the electric-field-induced lattice strain (intrinsic contribution) for each composition (More information about the domain switching and the electric-field-induced lattice strain contributions are given in the Supplementary Information, section B).

\subsection{Microstructural characterization}

The microstructure was evaluated on polished and thermally etched samples $\left(1000^{\circ} \mathrm{C}\right.$ for $\left.5 \mathrm{~min}\right)$ using a Field Emission Scanning Electron Microscope, FE-SEM (Hitachi S-4700). The microscope was coupled with a Themo NORAN x-sight energy dispersive X-ray spectrometer (EDXS), from Thermo Scientific Instruments, for chemical elemental analysis. The grain size distributions (GSD) and the average grain size (AGS) were measured from the FE-SEM micrographs using an image analysis 
This is the post-print (i.e. final draft post-refereeing) of the publication.

The final publication is available at Elsevier via http://dx.doi.org/ 10.1016/j.jeurceramsoc.2017.04.045

program (Leica Qwin, Leica Microsystems Ltd, Cambridge, England) considering more than 300 grains.

\subsection{Electrical Characterization:}

Silver paste was coated on both sides of the sintered samples for the electrical measurements. Room temperature ferroelectric properties were measured by using a hysteresis meter (RT 6000 HVS, RADIANT Technologies). The dielectric properties were determined at different temperatures and frequencies using an impedance analyzer HP4294A. In order to test the piezoelectric properties, the samples were polarized under a direct current $(d c)$ electric field of $4 \mathrm{kV} / \mathrm{mm}$ in a silicone oil bath at 25 ${ }^{\circ} \mathrm{C}$ for $30 \mathrm{~min}$ [44]. The piezoelectric constant $d_{33}$ was measured using a piezo $d_{33}$ meter (YE2730A $d_{33}$ METER, APC International, Ltd., USA) at room temperature.

\section{Results and discussion}

\subsection{Evolution of the polymorphic behaviour}

Figure 1a shows the XRD patterns of KNL-(NTS) ${ }_{1-x} Z_{5 \times} / 4$ ceramics. Diffraction patterns correspond to a perovskite structure without secondary impurity phases for $x=0.005,0.01$ and 0.03 . However, the presence of two minor secondary phases has been detected in un-doped ceramics $(x=0.00)$ and in the high-doped ceramics $(x=0.05)$. These secondary impurity phases can be attributed to the tetragonal tungsten-bronze (TTB) $\mathrm{K}_{6} \mathrm{LiNb}_{6} \mathrm{O}_{17}$ (PDF\# 40-0349) [10,14,34] and the $\mathrm{ZrO}_{2}$ (PDF\# 37-1484) phases. The absence of secondary phases in the doped ceramics with a compositional range of $0.005 \leq x \leq 0.03$ is a remarkable result, because TTB phases are commonly present in sintered alkaline niobates affecting piezoelectric response $[10,34]$. In addition, the results suggest that $\mathrm{KNL}-\mathrm{NTS}$ and $\mathrm{ZrO}_{2}$ form a limited solid solution.

The insert in Figure 1 shows a detail of the XRD diffraction pattern in the $2 \theta$ range from $44.5^{\circ}$ to $47^{\circ}$ of the KNL-(NTS) $)_{-x} \mathrm{Zr}_{5 \times / 4}$ ceramic system as a function of the $\mathrm{Zr}^{4+}$ content. The splitting of the (200) 
This is the post-print (i.e. final draft post-refereeing) of the publication.

The final publication is available at Elsevier via http://dx.doi.org/ 10.1016/j.jeurceramsoc.2017.04.045

cubic peak into the (200) and (002) reflections, corresponding to the expected non-cubic symmetry of these samples at room temperature, is shown. Peaks evolve from two defined signals at $45.3^{\circ}$ and $45.97^{\circ}$ for the undoped sample to two overlapped peaks at $45.65^{\circ}$ and $45.8^{\circ}$ for the highest $\mathrm{Zr}^{4+}$ content. All patterns can be fitted to the sum of four Lorentzian peaks, corresponding to two tetragonal peaks and two orthorhombic peaks of the perovskite phase. All samples present a polymorphic behaviour, which is associated with the room temperature coexistence of the tetragonal, $(T, \mathbf{P 4 m m})$, and orthorhombic, $(\mathrm{O}, \mathrm{Amm} 2)$, symmetries. The coexistence of different polymorphs $(T$ and $O)$ in KNLNTS ceramics were previously reported $[10,33,45]$. However, the polymorphic behaviour of KNL-(NTS) $)_{1-x} \mathrm{Zr}_{5 \times / 4}$ ceramics shows a clear dependence on the $\mathrm{Zr}^{4+}$ content (see insert in Figure 1). Thus, the compositions with $0.00 \leq x \leq 0.01$ have a room-temperature coexistence of $\boldsymbol{O}-\boldsymbol{T}$ phases, the peaks associated with $T$ symmetry being most relevant. However, a different trend is detected for the compositions with high $\mathrm{Zr}^{4+}$ contents $(0.03 \leq x \leq 0.05)$. In this compositional range, the peaks associated with orthorhombic symmetry are more relevant than in the ceramics with low $\mathrm{Zr}^{4+}$ contents, which implies a stabilization of orthorhombic symmetry at high $\mathrm{Zr}^{4+}$ concentrations (see insert in Fig. 1). 
This is the post-print (i.e. final draft post-refereeing) of the publication.

The final publication is available at Elsevier via http://dx.doi.org/ 10.1016/j.jeurceramsoc.2017.04.045
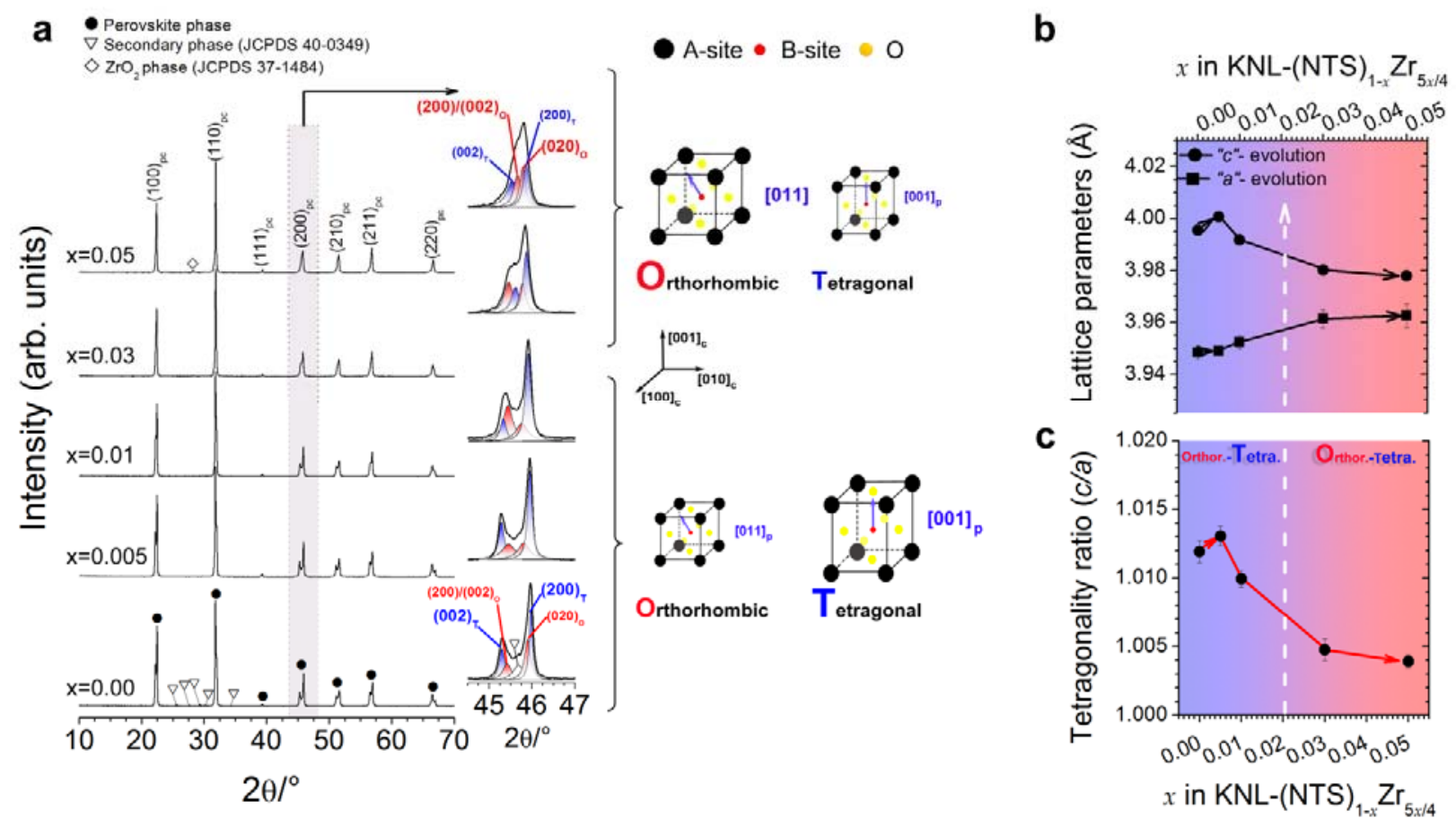

Figure 1| Identification of Phase Coexistence on the KNL-(NTS) 1- $\mathrm{X} \mathrm{Zr}_{5 \times / 4}$ Ceramics by XRD: The figure shows X-ray diffraction patterns of KNL-(NTS) $)_{1-x} Z r_{5 x / 4}$ ceramics. Diffraction peaks associated with the occurrence of the secondary phases are detected for $x=0.00$ and 0.05 , which are indicated by triangles and rhomboids symbols. The figure insert (region marked in grey on main panel) shows a detail of the XRD diffraction pattern in the $2 \theta$ range from $44.5^{\circ}$ to $47^{\circ}$. All patterns are fitted to the sum of four Lorentzian peaks, which are indexed as two tetragonal peaks (in blue) plus two orthorhombic peaks (in red) of the perovskite phase ( $T$ : Tetragonal symmetry and $O$ : Orthorhombic symmetry). Additionally, a schematic phase coexistence is shown on the right of the insert. The panels (b) and (c) show the lattice parameters evolution and the tetragonality ratio (c/a) of KNL-(NTS) ${ }_{1-x} Z r_{5 x / 4}$ ceramics, respectively.

To identify clearly the evolution of the polymorphic behaviour, the XRD data for different $\mathrm{Zr}^{4+}$ amounts are retrieved and the lattice parameters calculated, as shown in Figures 1b-c. As may be observed, an intermediate state around $x \sim 0.02$ is seen to appear, in which the lattice parameters " $a$ " and " $c$ " tend to converge (Figure 1b) causing a decrease in the structural distortion, $c / a$ (Figure 1c). The calculated $c / a$ ratio evolves from 1.014 for $x=0.00$ (pure KNL-NTS) to 1.004 for $x=0.05$. However, it is worth pointing out that the higher tetragonality ratio (1.016) is obtained for $x=0.005$, revealing the stabilization of the tetragonal symmetry at very low $\mathrm{Zr}^{4+}$ concentrations. More importantly, this large tetragonal distortion could lead to a large electrical polarization [46,47]. 
This is the post-print (i.e. final draft post-refereeing) of the publication.

The final publication is available at Elsevier via http://dx.doi.org/ 10.1016/j.jeurceramsoc.2017.04.045

The polymorphic behaviour evolution may be related to the solubility of $\mathrm{Zr}^{4+}$ ions in the perovskite structure and, consequently, to the chemical homogeneity of the system. The perovskite lattice is unable to accommodate the nominal $\mathrm{Zr}^{4+}$ content when this implies an excess in the B-site. Thus, the corresponding excess should be compensated by the eviction of some $\mathrm{Nb}^{5+}$ ions, with the subsequent transformation of the perovskite structure towards an orthorhombic symmetry. Finally, the appearance of the secondary phase $\left(\mathrm{ZrO}_{2}\right)$ indicates the limit for the B-site replacement. To sum up, the PPB can be modulated by chemical modifications such as the variation of the $\mathrm{B}$-site of the $\mathrm{ABO}_{3}$ perovskite structure with $\mathrm{Zr}^{4+}$. This is readily demonstrated in Figure 1, where there are two different symmetries $(O$ and $T)$ coexisting in the system at room temperature, but the relative volume fractions of the phases evolve as a function of the $\mathrm{Zr}^{+4}$ content. This fact suggests that the piezoelectric properties of the system will be affected by the modification of the multiphase coexistence or, in other words, by intrinsic factors.

\subsection{Identification of the phase transition temperatures}

Additional information concerning the effects of the $\mathrm{Zr}^{4+}$ doping on the phase transformations of the KNL-(NTS) 1-x $\mathrm{Zr}_{5 \times / 4}$ ceramic system can be obtained from the dielectric permittivity versus temperature curves. Figure 2a shows the temperature dependence of the dielectric constant $\varepsilon_{\mathrm{r}}$ as a function of $\mathrm{Zr}^{4+}$ content. The crystallographic structure of the system evolves from a paraelectric cubic $(C)$ phase at high temperatures to a ferroelectric $O$ phase at low temperatures, passing through a ferroelectric $T$ phase. Therefore, the transition temperatures are correspondingly defined as $T_{\mathrm{O}-\mathrm{T}}$, and $T_{\mathrm{C}}$ (or Curie temperature). All compositions exhibit two dielectric anomalies that are associated with the corresponding $T_{\mathrm{O}-\mathrm{T}}$ and $\mathrm{T}_{\mathrm{C}}$ transition temperatures. Although only $T_{\mathrm{C}}$ can be precisely determined from the $\varepsilon_{\mathrm{r}}$ versus $T$ data, an evolution of the $T_{\mathrm{O}-\mathrm{T}}$ temperature can be easily identified (Figure $\mathbf{2 b}$ ). Considering the results from both XRD patterns and $\varepsilon_{\mathrm{r}}$-T curves, two scenarios can be distinguished, depending on the doping content. The first of these scenarios, for a low doping range, corresponds to 
This is the post-print (i.e. final draft post-refereeing) of the publication.

The final publication is available at Elsevier via http://dx.doi.org/ 10.1016/j.jeurceramsoc.2017.04.045

compositions that present room temperature $\boldsymbol{O}-\boldsymbol{T}$ phase coexistence with a predominant $\boldsymbol{T}$ phase. The second, for a high doping range, corresponds to compositions for which the $O-T$ phase boundary evolves towards the stabilization of the $\boldsymbol{O}$ phase, thereby leading to an increase of the $T_{\mathrm{O}-\mathrm{T}}$ temperature. In addition, the elimination of the TTB phase may also contribute to the $T_{\mathrm{C}}$ increasing for the lowest $\mathrm{Zr}^{4+}$ content.

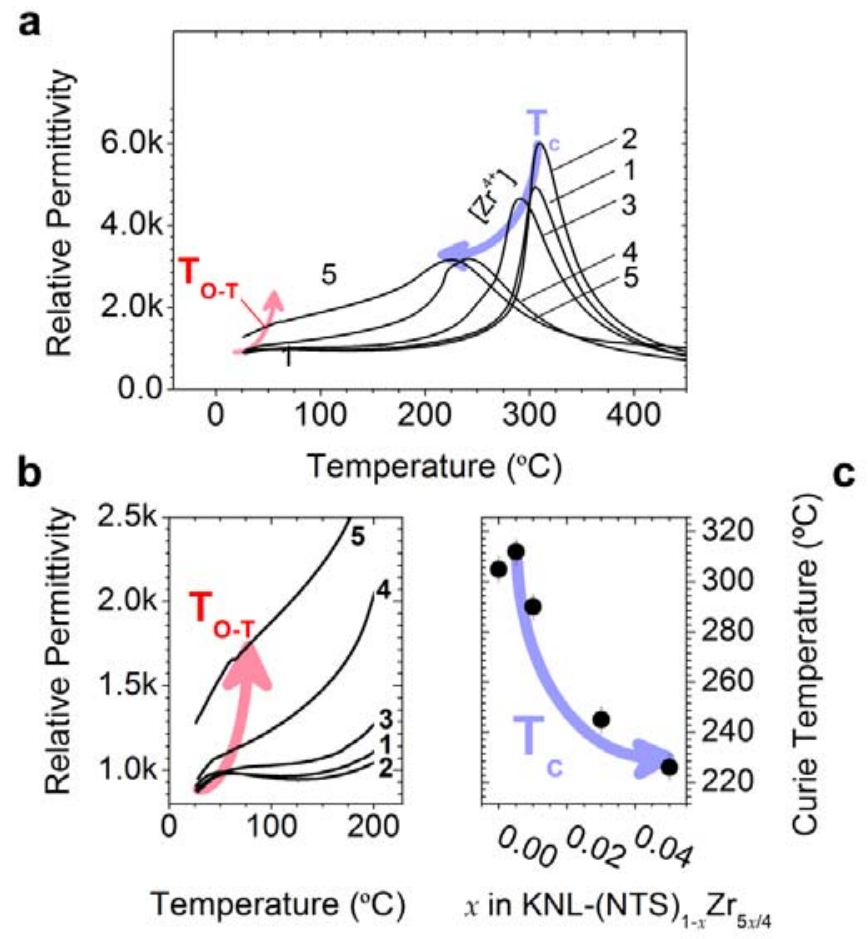

Figure 2| Identification and Influence of the $\mathrm{Zr}^{4+}$ content on Phase Transitions: (a) Temperature dependence of real permittivity of $\mathrm{KNL}-(\mathrm{NTS})_{1-\mathrm{x}} \mathrm{Zr}_{5 \times / 4}$ sintered ceramics at $100 \mathrm{kHz}$. Panel (b) shows a detail of the $\varepsilon_{\mathrm{r}}-\mathrm{T}$ curves in the temperature range from 25 to $200{ }^{\circ} \mathrm{C}$. Panel (c) shows the evolution of the $T_{\mathrm{c}}$ as a function of the $\mathrm{Zr}^{4+}$ content (the resolution of the phase transition temperatures, $T$ c, was estimated as $\pm 5^{\circ} \mathrm{C}$ ). The compositions represented in (a) and (b) are labelled as follows: (1) $x=0.00$; (2) $x=0.005$; (3) $x=0.01$; (4) $x=0.03$; and (5) $x=0.05$.

Additionally, Figure 2c shows the influence of the $\mathrm{Zr}^{+4}$ content on $\mathrm{T}_{\mathrm{C}}$. The $\mathrm{Zr}^{+4}$ addition effect has two discernible features. Firstly, $T_{C}$ increases for low $\mathrm{Zr}^{4+}$ content (i.e., $T_{\mathrm{C}} \sim 315{ }^{\circ} \mathrm{C}$ for $\mathrm{x}=0.005$, while $T_{\mathrm{C}} \sim 305^{\circ} \mathrm{C}$ for $\mathrm{x}=0.00$ ), which may mean that compositions with a low amount of appropriate doping exhibit higher $T_{\mathrm{C}}$. This is an interesting finding, since the obtention of piezoceramics combining a good 
This is the post-print (i.e. final draft post-refereeing) of the publication.

The final publication is available at Elsevier via http://dx.doi.org/ 10.1016/j.jeurceramsoc.2017.04.045

comprehensive performance of piezoelectric properties and high $T_{C}$ is highly desirable. Secondly, $T_{C}$ quickly decreases as the $\mathrm{Zr}^{4+}$ content becomes greater (i.e., for $\mathrm{x}>0.005$ ). Furthermore, an increase in the phase transition diffusivity is observed as the $\mathrm{Zr}^{4+}$ content rises; in particular, for $\mathrm{x} \geq 0.03$, as shown in Supplementary Information, section C (see Figure S2). These results suggest that a high $\mathrm{Zr}^{4+}$ doping makes the phase transition more diffuse because of chemical heterogeneities.

\subsection{How intrinsic factors affect piezoelectric properties}

The high density of the KNL-(NTS) $)_{1-x} Z_{5 x / 4}$ ceramics allows us to measure the ferroelectric response, and therefore to attempt a correlation of ferroelectric properties with the observed structural evolution. For a better understanding of the relationships between physical-chemical phenomena and electromechanical properties of this system, the electric field dependence of polarization ( $P$-E loops) as a function of $\mathrm{Zr}^{4+}$ content were measured at room temperature. As shown in Figure 3a, all compositions exhibit typical hysteresis loops, which reveal their ferroelectric character. However, the ferroelectric properties are strongly dependent on the composition and, consequently, on the evolution of PPB. Thus, the compositions with low $\mathrm{Zr}^{4+}$ content $(0.00 \leq \mathrm{x} \leq 0.01)$ exhibit good square hysteresis loops, while a poor ferroelectric behaviour, together with a slim $P-E$ loop, are shown for $x>0.01$. To evaluate the effect of $\mathrm{Zr}^{4+}$ content accurately on the ferroelectric properties, the evolution of the remanent polarization $\left(P_{r}\right)$ and the coercive field $\left(E_{C}\right)$ are plotted in Figure $\mathbf{3} \mathbf{b}$. As can be observed, $P_{r}$ increases up to $20 \mu \mathrm{C} \cdot \mathrm{cm}^{-2}$ in $\mathrm{x}=0.005$ and then sharply decreases as the $\mathrm{Zr}^{+4}$ content increases. The $E_{\mathrm{C}}$ exhibits a similar trend; i.e. it increases as the $\mathrm{Zr}^{4+}$ content increases, reaching the higher value for $\mathrm{x}=$ 0.005 , and then decreases with the doping rise. Higher values of $P_{r}$ in compositions with $0.00 \leq \mathrm{x} \leq 0.01$, may be attributed to the stabilization of the $T$ phase on the PPB at room temperature, thereby confirming that the large tetragonal distortion, c/a ratio, obtained from the XRD measurement (Figure 1c), leads to an enhanced electrical polarization [47-50]. Moreover, the elimination of the TTB phase also contributes to the improvement of the ferroelectric properties. 
This is the post-print (i.e. final draft post-refereeing) of the publication.

The final publication is available at Elsevier via http://dx.doi.org/ 10.1016/j.jeurceramsoc.2017.04.045

a $E(\mathrm{kV} / \mathrm{cm})$

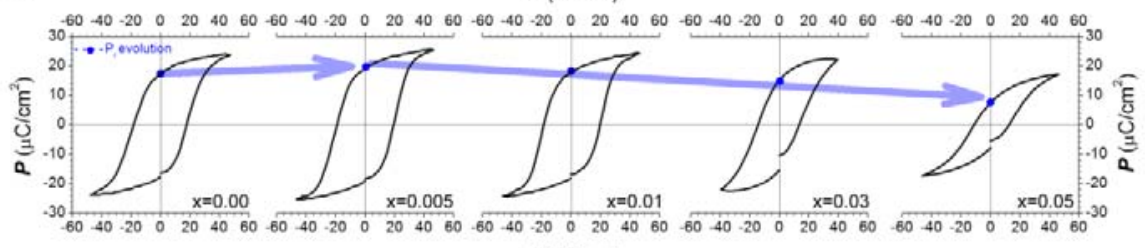

(1) $\boldsymbol{E}(\mathrm{kV} / \mathrm{cm})$

(2)
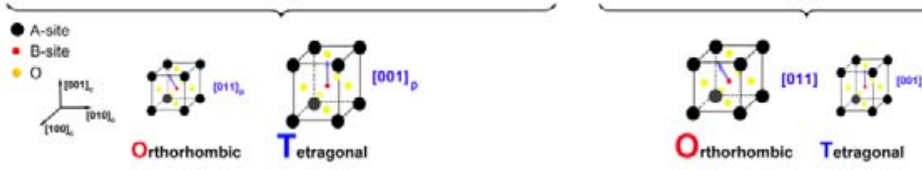

b
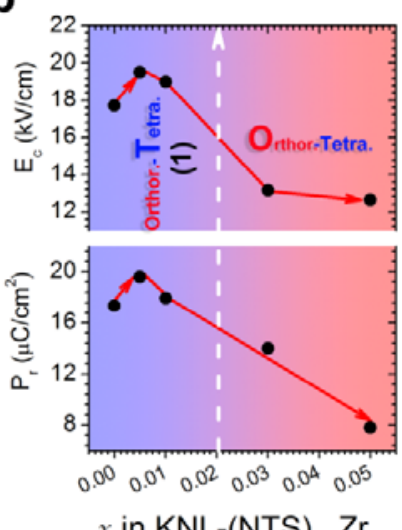

C

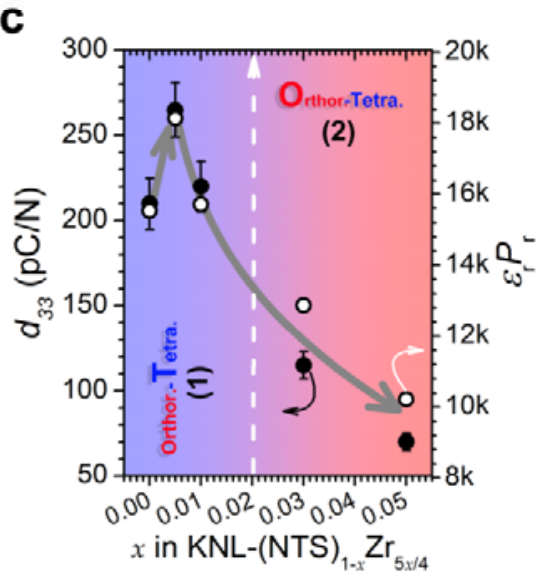

Figure 3 | Interrelationship between ferroelectric and piezoelectric responses: a Polarization versus electric field loops and $\mathbf{b}$ remanent polarization $\left(P_{r}\right)$ and coercive field $\left(E_{C}\right)$ values of the KNL-(NTS) $)_{-x} \mathrm{Zr}_{5 \times / 4}$ ceramics as a function of $x$. Panel $\mathrm{c}$ shows the piezoelectric coefficient $\left(d_{33}\right)$ and the product $\varepsilon_{\mathrm{r}} \mathrm{P}_{\mathrm{r}}$ versus $\mathrm{Zr}^{4+}$ content. Additionally, below the panel (a) a schematic representation of phase coexistence as a function of the composition is indicated. The blue and red areas delimit the compositional regions, which imply a stabilization of $\boldsymbol{T}$ symmetry (region marked as 1 ) or $\boldsymbol{O}$ symmetry (region marked as 2 ), depending on the compositions in the PPB at room temperature. The standard tolerance for the electrical properties is $\pm 10 \%$.

The direct piezoelectric coefficient, $d_{33}$, is determined by the electric charge response to a low external mechanical stress (linear conditions). The value of the $d_{33}$ is a commonly accepted quality indicator of the piezoelectric activity of a material. Therefore, increasing the $d_{33}$ becomes a major concern in order to improve the functional properties. From this perspective, enhanced dielectric and ferroelectric properties are desirable, since the piezoelectric response is related to these properties through the $d_{33} \alpha \varepsilon_{r} P_{r}$ relationship [51,52]. In consequence, an enhancement of the piezoelectric 
This is the post-print (i.e. final draft post-refereeing) of the publication.

The final publication is available at Elsevier via http://dx.doi.org/ 10.1016/j.jeurceramsoc.2017.04.045

properties is possible for higher $P_{r}$ (in particular for compositions with $0.00 \leq \mathrm{x} \leq 0.01$ ), even though the $\varepsilon_{\mathrm{r}}$ remains constant.

The $P_{r}$ and, consequently, the $d_{33}$, seem to be definitively related to the main phase governing the PPB. To verify this relation, the ceramics were polarized and the $d_{33}$ was measured. Both the $d_{33}$ and $\varepsilon_{\mathrm{r}} P_{\mathrm{r}}$ product are plotted as a function of the $\mathrm{Zr}^{4+}$ content, as shown in Figure 3c. A similar changing tendency in both $d_{33}$ and $\varepsilon_{\mathrm{r}} P_{\mathrm{r}}$ curves occurs in all compositions; i.e., $d_{33}$ and $\varepsilon_{\mathrm{r}} P_{\mathrm{r}}$ first increase and then decrease as $\mathrm{x}$ increases, reaching a peak value of $d_{33} \sim 265 \mathrm{pC} / \mathrm{N}$ for $\mathrm{x}=0.005$. The ceramics doped with low $\mathrm{Zr}^{+4}$ content $(0 \leq \mathrm{x} \leq 0.01)$ show good piezoelectric properties while the piezoelectricity degrades with an increase in the $\mathrm{Zr}^{4+}$ content $(x \geq 0.03)$. Therefore, our results show that the enhanced piezoelectricity of the system may partly result from the increase in structural distortion, $c / a$, as a consequence of the tetragonal symmetry stabilization around the PPB.

Summarizing, the existence of a room temperature PPB is crucial in KNN-based material because it provides the polarization rotation path for the enhanced piezoelectric properties near the phase boundary [53-55], making the ceramic more polarizable. In this context, we found that the piezoelectricity in rich $T$ regions $(0 \leq x \leq 0.01)$ is higher than that in rich $O$ regions $(x \geq 0.03)$. Therefore, the piezoelectric activity is directly related to the $T_{\mathrm{O}-\mathrm{T}}$, as has been demonstrated by $\mathrm{XRD}$ and $\varepsilon_{\mathrm{r}}-T$ curves.

\subsection{How an extrinsic factor may affect piezoelectric properties}

As demonstrated in the above subsection, the crystallographic nature of the PPB (intrinsic factor) plays a relevant role in the functional properties of the piezoceramics. Nevertheless, it is also necessary to take into account the microstructural features (extrinsic factors) of these materials. For instance, it is well-known that there is a strong dependency of the piezoelectric properties on the grain size in perovskite systems such as $\mathrm{Pb}(\mathrm{Zr}, \mathrm{Ti}) \mathrm{O}_{3}$ and $\mathrm{BaTiO}_{3}$ [56-58]. From this perspective, the relationships 
This is the post-print (i.e. final draft post-refereeing) of the publication.

The final publication is available at Elsevier via http://dx.doi.org/ 10.1016/j.jeurceramsoc.2017.04.045

between microstructure and piezoelectric properties are studied here by means of FE-SEM micrograph, as shown in Figure 4. As may be observed, the microstructure (Figs. 4a-e) and the grain size distribution (GSD) [Figs. $4 \mathbf{f}-\mathbf{j}$ ] of the ceramics are clearly influenced by adding $\mathrm{Zr}^{4+}$ ions. The average grain size (AGS) of the ceramics increases with increasing $\mathrm{Zr}^{4+}$ content (Fig. 4a-b) and then drops on further increase of the $\mathrm{Zr}^{4+}$ content (Fig. 4c-e). Analysis of the GSD evolution (Fig $\mathbf{4 f - j}$ ) leads to two remarkable observations; firstly, the ceramics with $0.00 \leq x \leq 0.005$ have a multimodal distribution of grain sizes; that is, bigger grains are surrounded by smaller ones, and secondly, the GSD evolves toward a unimodal distribution as the $\mathrm{Zr}^{+4}$ content increases. Thus, it is possible to assume that the system evolves to a more homogeneous grain size distribution, but showing substantially smaller grain sizes. The observed dissimilar behaviours could be attributed to the fact that, in the first place, the sintering process of this system occurs due to the presence of a liquid phase for low $\mathrm{Zr}^{4+}$ contents $(0.00$ $\leq \mathrm{x} \leq 0.005$ ) [10]. Hence, the formation of a limited amount of liquid phase during sintering promotes the grain growth, thereby giving rise to the increase in grain size. In the second place, for high $\mathrm{Zr}^{4+}$ contents $(0.01 \leq \mathrm{x} \leq 0.05)$, the $\mathrm{Zr}^{4+}$ ions act as a grain growth inhibitor that transforms the grains into more cube-shaped grains with sharp edges and corners. 
This is the post-print (i.e. final draft post-refereeing) of the publication.

The final publication is available at Elsevier via http://dx.doi.org/ 10.1016/j.jeurceramsoc.2017.04.045
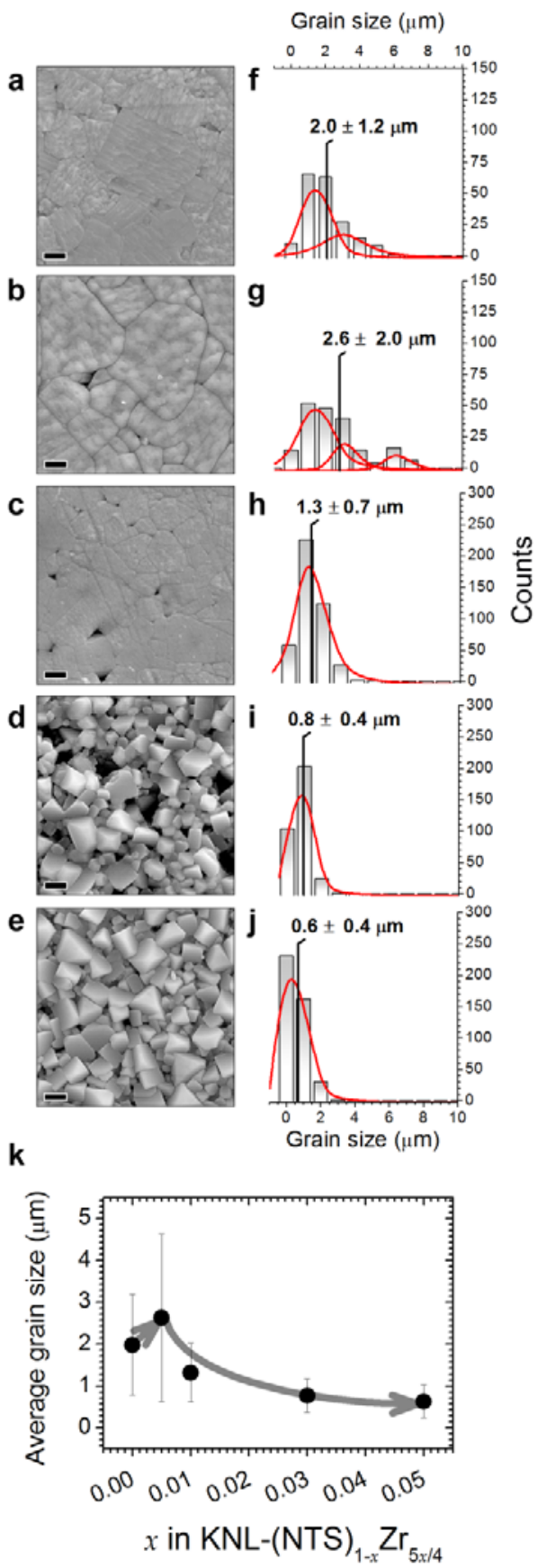

Figure $4 \mid \mathrm{Zr}^{4+}$ content effect on microstructure: (a-e) Sequence of FE-SEM images showing the evolution of the microstructure in the KNL-(NTS) ${ }_{1-x} \mathrm{Zr}_{5 x / 4}$ ceramics with different contents of $\mathrm{Zr}^{4+}$, where (a) corresponds to $x=0.00,(\mathbf{b})$ to $x=$ 0.005 , (c) to $x=0.01,(\mathbf{d})$ to $x=0.03$, and (e) to $x=0.05$. Scale bar, $1 \mu \mathrm{m}$. (f-j) Sequence of grain size distributions (GSDs) for (f) $x$ $=0.00,(\mathbf{g}) x=0.005,(\mathbf{h}) x=0.01,(\mathbf{i}) x=0.03$, and $(\mathbf{j}) x=0.05$. (k) Evolution of the average grain size (AGS) as a function of the $\mathrm{Zr}^{4+}$ content. The error bars show the standard deviation of the AGS of each sample. 
This is the post-print (i.e. final draft post-refereeing) of the publication.

The final publication is available at Elsevier via http://dx.doi.org/ 10.1016/j.jeurceramsoc.2017.04.045

The AGS evolution as a function of $\mathrm{Zr}^{4+}$ contents obtained from GSDs (Fig. $\mathbf{4 f - j}$ ) is displayed in Figure 4k. As may be observed, the AGS decreases from $~ 2.0 \pm 1.2 \mu \mathrm{m}$ in the undoped ceramic $(\mathrm{x}=$ $0.00)$, to sub-micrometer size of $\sim 0.6 \pm 0.4 \mu \mathrm{m}$ for the ceramics with the highest $\mathrm{Zr}^{+4}$ content $(\mathrm{x}=0.05)$. It is widely accepted that piezoelectric properties, and in particular the $d_{33}$, decrease for submicron grain sizes due to domain size reduction that increases domain wall density, thereby restricting the extrinsic contribution $[17,56-60]$. In the same way, smaller grain sizes could also hinder domain wall motion by the presence of grain boundaries [56-60]. It is interesting to point out that the same behaviour is displayed in both $d_{33}$ (Fig. 3c) and AGS (Fig. 4k) versus $\mathrm{Zr}^{4+}$ content; that is, $d_{33}$ and AGS first increase and then decrease as $\mathrm{x}$ increases, reaching a peak value of $265 \mathrm{pC} / \mathrm{N}$ and $2.6 \mu \mathrm{m}$, respectively, for $\mathrm{x}=$ 0.005. Finally, this behaviour allows us to infer that, in addition to the intrinsic factor, the extrinsic factors (e.g. microstructure) play an important role in the development of good piezoelectric properties; that is, the increased grain size contributes to the enhancement of the piezoelectric properties.

\subsection{Domain switching and lattice strain contributions}

Piezoelectricity appears in ferroelectric ceramics once the random ferroelectric domains have been aligned through the poling process [61]. This process plays a crucial role in the piezoelectric performance of piezoceramics, because $d_{33}$ is directly related to the polarization state of the sample, which is normally linked to $P_{\mathrm{r}}$. In general, the poling process comes from the $180^{\circ}$ domain reversal and the non- $180^{\circ}$ domain reorientation. However, a field-induced phase transformation may also promote the poling process in ceramics that possess phase coexistence near the poling temperature. Therefore, in addition to extrinsic factors (domain contribution), intrinsic factors (crystallographic nature of the PPB) may be instrumental for reaching an optimum polarization state in PPB systems. In fact, the nature of the PPB determines the domain structure, thereby influencing the domain reorientation. 
This is the post-print (i.e. final draft post-refereeing) of the publication.

The final publication is available at Elsevier via http://dx.doi.org/ 10.1016/j.jeurceramsoc.2017.04.045

Thus, an interrelationship between both intrinsic and extrinsic factors is the key to the poling process in PPB systems.

a

Unpoled state $\quad$ Poled state

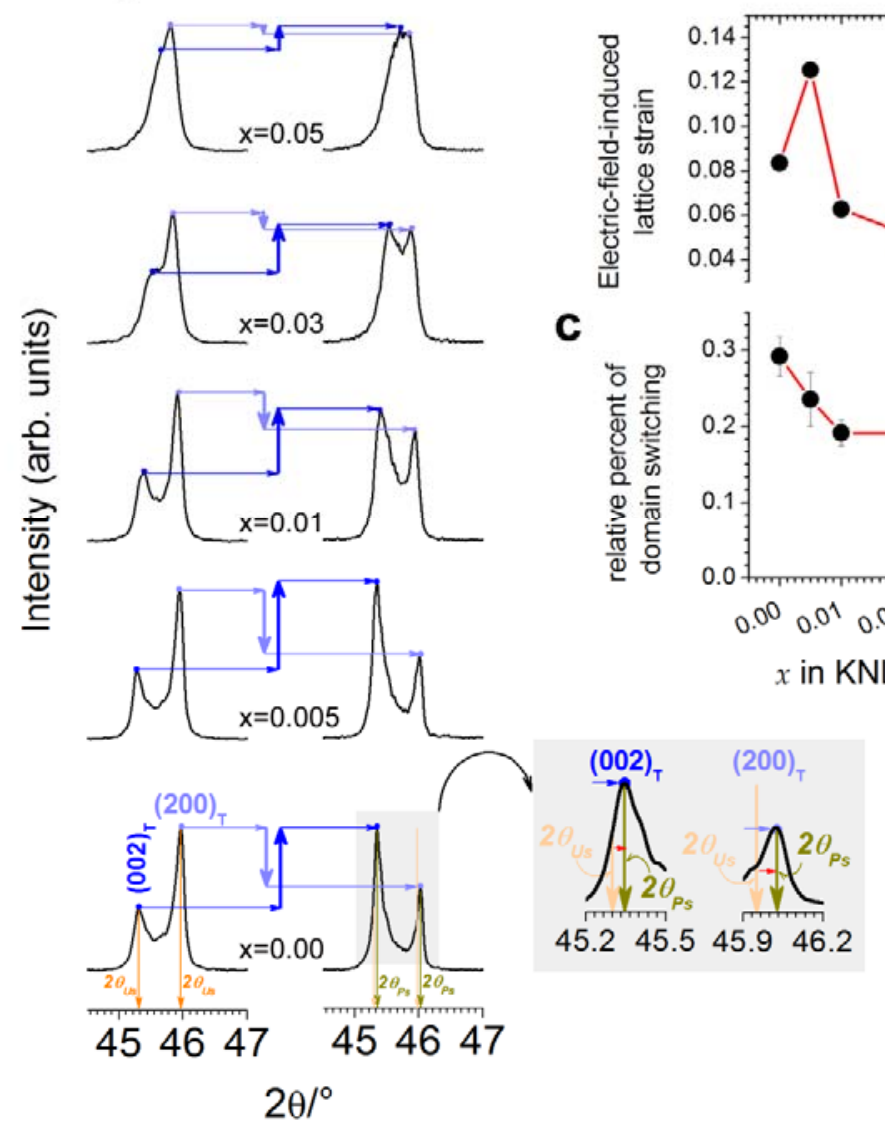

Figure 5|Domain switching and lattice strain contribution to poling from XRD: (a) Detail of the XRD pattern of KNL-(NTS) $)_{1-x} Z r_{5 x / 4}$ ceramics in the $2 \theta$ range from $44.5^{\circ}$ to $47^{\circ}$. Panel (a) shows the evolution of the (200) pseudocubic reflection before and after of the poling process, which is represented by the blue arrows. The inset in (a) shows the shift of the (002) and (200) peaks when the samples are polarized. The orange arrows represent the peak positions in the unpoled state, while the dark yellow arrows show the peak positions in the poled state. (b) Absolute value of lattice strain versus $\mathrm{Zr}^{4+}$ content

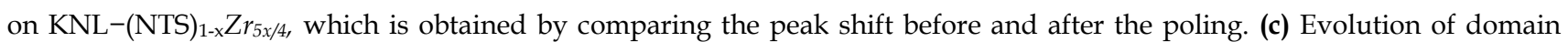
switching as a function of the $\mathrm{Zr}^{4+}$ content by comparing the peak intensity before and after poling. Error bars are included in (b) and (c) plots. 
This is the post-print (i.e. final draft post-refereeing) of the publication.

The final publication is available at Elsevier via http://dx.doi.org/ 10.1016/j.jeurceramsoc.2017.04.045

In this regard, the evolution of the intrinsic and extrinsic contributions to poling as a function of the $\mathrm{Zr}^{4+}$ content (i.e., in different PPB conditions) is thus studied. The non- $180^{\circ}$ domain reorientation (extrinsic contribution) can be detected by the change in the intensities of the (002) and (200) XRD peaks. Moreover, the shift in the peak positions enables the lattice strain (intrinsic contribution) to be obtained as a result of the poling process (More information about the domain switching and the electricfield-induced lattice strain contributions are given in the Supplementary Information, section B). Figure 5a shows a detail of the XRD pattern of the KNL-(NTS) $)_{1-x} \mathrm{Zr}_{5 \times / 4}$ ceramics in their poled and unpoled states. As may be seen, a notable change in the intensity profile occurs as a result of the domain reorientation during the poling process. The relative intensity of the (002) reflection increases, whereas the (200) ones decreases. Furthermore, the positions of both reflections shift to higher $2 \theta$ values after the polarization field has been applied, as is shown in detail in the insert in Figure 5a.

The electric field-induced lattice strain and the relative percent of non- $180^{\circ}$ domain switching are shown in Figures $\mathbf{5 b}$ and $\mathbf{5 c}$, respectively. Results show that both intrinsic and extrinsic contributions maximize for lower values of $\mathrm{Zr}^{4+}$ content, thereby ratifying that the stabilization of the $T$ phase into the PPB enhances piezoelectric properties through an improvement of the poling process. Nonetheless, intrinsic and extrinsic contributions do not follow the same trend. The lattice strain reaches a maximum value for $x=0.005$, while the domain switching undergoes a continuous decrease from the value at $x=0.00$ to the value at $x=0.05$. Hence, the results demonstrate that a direct connection exists between the intrinsic contribution maximum and the higher piezoelectric response. In other words, the crystallographic nature of the PPB appears to be a decisive factor for enhancing piezoelectric response in KNN-based systems. 
This is the post-print (i.e. final draft post-refereeing) of the publication.

The final publication is available at Elsevier via http://dx.doi.org/ 10.1016/j.jeurceramsoc.2017.04.045

\section{Conclusion}

The decisive influence of the crystallographic nature of the polymorphic phase boundary (PPB) on the piezoelectric properties of $(\mathrm{K}, \mathrm{Na}) \mathrm{NbO}_{3}-\mathrm{LiTaO}_{3}-\mathrm{LiSbO}_{3}(\mathrm{KNL}-\mathrm{NTS})$ system is revealed in this work. The KNL-NTS is synthesized by replacing B-sites with $\mathrm{Zr}^{4+}$ ions, thereby leading to the [KNL-(NTS)1$\left.{ }_{x} \mathrm{Zr}_{5 / 4 x}\right]$ system. The control of phase coexistence between tetragonal $(T)$ and orthorhombic $(O)$ symmetries in the PPB is carried out by modifying the $\mathrm{Zr}^{4+}$ content. The grain size is simultaneously modulated, obtaining a larger grain size in compositions that present a $T$-rich PPB. The results show that the stabilization of the $T$ phase in the PPB plays a fundamental role in terms of the piezoelectric property enhancement in potassium-sodium niobate-based lead free piezoceramics. More importantly, the simultaneous control of both the PPB crystallographic nature and the grain size through compositional engineering and/or novel processing routes seem to constitute the cornerstone for the increased piezoelectric performance. Additionally, the elimination of the tetragonal tungsten-bronze phase with the lowest $\mathrm{Zr}^{4+}$ addition also contributes to the ferroelectric and piezoelectric properties enhancement.

\section{Acknowledgements}

The authors are grateful to CONICET, ANPCyT, University of Mar del Plata (Argentina) and to the MINECO (Spain) project MAT2013-48009-C4-P for the financial support provided for this research. The Spanish National Research Council (CSIC) under project NANOMIND CSIC 201560E068. F. R-M is also indebted to MINECO for a 'Ramon y Cajal' contract (ref: RyC-2015-18626), which is co-financed by the European Social Fund. 
This is the post-print (i.e. final draft post-refereeing) of the publication.

The final publication is available at Elsevier via http://dx.doi.org/ 10.1016/j.jeurceramsoc.2017.04.045

\section{References}

[1] B. Jaffe, R.S. Roth and S. Marzullo, Properties of piezoelectric ceramics in the solid-solution series lead titanate-lead zirconate-lead oxide: Tin oxide and lead titanate-lead hafnate, J. Res. Natl. Bur. Stand. 55 (1955) 239-243.

[2] E. Cross, Materials science: Lead-free at last, Nature 432 (2004) 24-25.

[3] http://ec.europa.eu/environment/waste/weee/index_en.htm (last access: 21 January 2011).

[4] T. R. Shrout and S. Zhang, Lead-free piezoceramics: Alternatives for PZT?, J. Electroceram. 19 (2007) 111-124.

[5] J. Rödel, W. Jo, K. Seifert, E.M. Anton, T. Granzow and D. Damjanovic, Perspective on the development of lead-free piezoceramics, J. Am. Ceram. Soc. 89 (2009) 1153-1177.

[6] J. Rödel, K.G. Webber, R. Dittmer, W. Jo, M. Kimura and D. Damjanovic, Transferring lead-free piezoelectric ceramics into application, J. Eur. Ceram. Soc. 35 (2015) 1659-1681.

[7] T. Takenaka and H. Nagata, Current status and prospects of lead-free piezoelectric ceramics, J. Eur. Ceram. Soc. 25 (2005) 2693-2700.

[8] J. Camargo, L.A. Ramajo, F. Rubio-Marcos and M. Castro, Ferroelectric properties of $\mathrm{Bi}_{0.5}\left(\mathrm{Na}_{0.8} \mathrm{~K}_{0.2}\right)_{0.5} \mathrm{TiO}_{3}$ ceramics, Advanced Materials Research 975 (2014) 3-8

[9] I. Levin and I.M. Reaney, Nano- and mesoscale structure of $\mathrm{Na}_{1 / 2} \mathrm{~B}_{1 / 2} \mathrm{TiO}_{3}$ : A TEM perspective, Adv. Funct. Mater. 22 (2012) 3445-3452.

[10] F. Bortolani, A. Campo, J.F. Fernandez, F. Clemens and F. Rubio-Marcos, High strain in (K,Na) $\mathrm{NbO}_{3}$-based lead-free piezoelectric fibers, Chem. Mater. 26 (2014) 3838-3848.

[11] W. Ge, J. Li, D. Viehland, Y. Chang and G.L. Messing, Electric-field-dependent phase volume fractions and enhanced piezoelectricity near the polymorphic phase boundary of $\left(\mathrm{K}_{0.5} \mathrm{Na}_{0.5}\right)_{1-x} \mathrm{Li}_{x} \mathrm{NbO}_{3}$ textured ceramics, Phys. Rev. B 83 (2011) 224110.

[12] Y. Saito, H. Takao, T. Tani, T. Nonoyama, K. Takatori, T. Homma, T. Nagaya and M. Nakamura, Lead-free piezoceramics, Nature 432 (2004) 84-87.

[13] K. Wang and J-F. Li, Domain engineering of lead-free Li-modified $(\mathrm{K}, \mathrm{Na}) \mathrm{NbO}_{3}$ polycrystals with highly enhanced piezoelectricity, Adv. Funct. Mater. 20 (2010) 1924-1929.

[14] F. Rubio-Marcos, P. Ochoa and J.F. Fernández, Sintering and properties of lead-free piezoceramics, J. Eur. Ceram. Soc. 13-15 (2007) 4125-4129.

[15] Y. Saito and H. Takao, Synthesis of polycrystalline platelike $\mathrm{KNbO}_{3}$ particles by the topochemical micro-crystal conversion method and fabrication of grain-oriented ( $\left.\mathrm{K}_{0.5} \mathrm{Na}_{0.5}\right) \mathrm{NbO}_{3}$ Ceramics, J. Eur. Ceram. Soc. 27 (2007) 4085-4092.

[16] Y. Guo, K.I. Kakimoto and H. Ohsato, Phase transitional behavior and piezoelectric properties of $\left(\mathrm{Na}_{0.5} \mathrm{~K}_{0.5}\right) \mathrm{NbO}_{3}-$ $\mathrm{LiNbO}_{3}$ ceramics, Appl. Phys. Lett. 85 (2004) 4121.

[17] F. Rubio-Marcos, A. Del Campo, R. López-Juárez, J.J. Romero and J.F. Fernández, . High spatial resolution structure of $(\mathrm{K}, \mathrm{Na}) \mathrm{NbO}_{3}$ lead-free ferroelectric domains, J. Mater. Chem. 22 (2012) 9714-9720.

[18] F-Z. Yao, K. Wang, W. Jo, K.G. Webber, T.P. Comyn, J-X. Ding, B. Xu, L-Q. Cheng, M-P. Zheng, Y-D. Hou and J-F. Li, Diffused phase transition boosts thermal stability of high-performance lead-free piezoelectrics, Adv. Funct. Mater. 26 (2016) 1217-1224.

[19] J-S. Zhou, K. Wang, F-Z. Yao, T. Zheng, J. Wu, D. Xiao, J. Zhu and J-F. Li, Multi-scale thermal stability of niobate-based lead-free piezoceramics with large piezoelectricity, J. Mater. Chem. C 3 (2015) 8780-8787. 
This is the post-print (i.e. final draft post-refereeing) of the publication.

The final publication is available at Elsevier via http://dx.doi.org/ 10.1016/j.jeurceramsoc.2017.04.045

[20] X. Wang, J. Wu, D. Xiao, J. Zhu, X. Cheng, T. Zheng, B. Zhang, X. Lou and X. Wang, Giant piezoelectricity in potassiumsodium niobate lead-free ceramics, J. Am. Chem. Soc. 136 (2014) 2905-2910.

[21] K. Wang, B-P. Zhang, J-F. Li and L-M. Zhang, Lead-free $\mathrm{Na}_{0.5} \mathrm{~K}_{0.5} \mathrm{NbO}_{3}$ piezoelectric ceramics fabricated by spark plasma sintering: Annealing effect on electrical properties. J Electroceram. 21 (2008) 251-254.

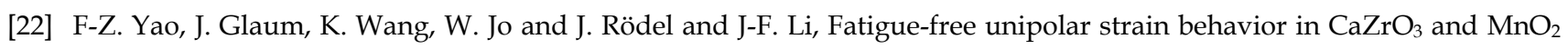
co-modified (K,Na) $\mathrm{NbO}_{3}$-based lead-free piezoceramics, Appl. Phys. Lett. 103 (2013) 192907.

[23] N. Liu, K. Wang, J-F. Li, and Z. Liu, Hydrothermal synthesis and spark plasma sintering of $(\mathrm{K}, \mathrm{Na}) \mathrm{NbO}_{3}$ lead-free piezoceramics, J. Am. Ceram. Soc. 92 (2009) 1884-1887.

[24] J. Wu, D. Xiao and J. Zhu, Potassium-sodium niobate lead-free piezoelectric materials: Past, present, and future of phase boundaries, Chem. Rev.115 (2015) 2559-2595.

[25] T. Zheng and J. Wu, Relationship between poling characteristics and phase boundaries of potassium-sodium niobate ceramics, ACS Appl. Mater. Interfaces 8 (2016) 9242-9246.

[26] X. Lv, J. Wu, S. Yang, D. Xiao and J. Zhu, Identification of phase boundaries and electrical properties in ternary potassium-sodium niobate-based ceramics, ACS Appl. Mater. Interfaces 8 (2016) 18943-18953.

[27] J. Venkatesh, V. Sherman and N. Setter, Synthesis and dielectric characterization of potassium niobate tantalate ceramics, J. Am. Ceram. Soc. 88 (2005) 3397-3404.

[28] X. Vendrell, J.E. García, F. Rubio-Marcos, D.A. Ochoa, L. Mestres and J.F. Fernández, Exploring different sintering atmospheres to reduce nonlinear response of KNN-modified piezoceramics, J. Eur. Ceram. Soc. 33 (2013) 825-831.

[29] F. Rubio-Marcos, P. Marchet, T. Merle-Méjean and J. F. Fernández, Role of sintering time, crystalline phases and symmetry in the piezoelectric properties of lead-free KNN-modified ceramics, Mater. Chem. Phys. 123 (2010) 91-97.

[30] T. Zheng, J. Wu, D. Xiao and J. Zhu, Composition-driven phase boundary and piezoelectricity in potassium-sodium niobate-based ceramics, ACS Appl. Mater. Interfaces 7 (2015) 20332-20341.

[31] K. Xu, J. Li, X. Lv, J. Wu, X. Zhang, D. Xiao and J. Zhu, Superior piezoelectric properties in potassium-sodium niobate lead-free ceramics, Adv. Mater. 28 (2016) 8519-8523.

[32] T. Iamsasri, G. Tutuncu, C. Uthaisar, S. Wongsaenmai, S. Pojprapai and J. L. Jones, Electric field-induced phase transitions in Li-modified $\mathrm{Na}_{0.5} \mathrm{~K}_{0.5} \mathrm{NbO}_{3}$ at the polymorphic phase boundary, J. Appl. Phys. 117 (2015) 024101.

[33] D.A. Ochoa, G. Esteves, J. L. Jones, F. Rubio-Marcos, J.F. Fernández and J.E. García, Extrinsic response enhancement at the polymorphic phase boundary in piezoelectric materials, Appl. Phys. Lett. 108 (2016) 142901.

[34] L. Ramajo, M. Castro, A. del Campo, J.F. Fernandez and F. Rubio-Marcos, Revealing the role of cationic displacement in potassium-sodium niobate lead-free piezoceramics by adding W6+ ions, J. Mater. Chem. C 3 (2015) 4168-4178.

[35] F. Rubio-Marcos, P. Marchet, J.J. Romero and J.F. Fernández, Structural, microstructural and electrical properties evolution of $(\mathrm{K}, \mathrm{Na}, \mathrm{Li})(\mathrm{Nb}, \mathrm{Ta}, \mathrm{Sb}) \mathrm{O}_{3}$ lead-free piezoceramics through $\mathrm{NiO}$ doping, J. Eur. Ceram. Soc. 31 (2011) 2309-2317.

[36] F. Rubio-Marcos, J.J. Reinosa, X. Vendrell, J.J. Romero, L. Mestres, P. Leret, J.F. Fernández and P. Marchet, Structure, microstructure and electrical properties of $\mathrm{Cu}^{2+}$ doped $(\mathrm{K}, \mathrm{Na}, \mathrm{Li})(\mathrm{Nb}, \mathrm{Ta}, \mathrm{Sb}) \mathrm{O}_{3}$ piezoelectric ceramics, Ceram. Int. 39 (2013) 4139-4149.

[37] P. Bomlai, P. Wichianrat, S. Muensit and S. J Milne, Effect of calcination conditions and excess alkali carbonate on the phase formation and particle morphology of $\mathrm{Na}_{0.5} \mathrm{~K}_{0.5} \mathrm{NbO}_{3}$ powders, J Am Ceram Soc. 90 (2007) 1650-1655. 
This is the post-print (i.e. final draft post-refereeing) of the publication.

The final publication is available at Elsevier via http://dx.doi.org/ 10.1016/j.jeurceramsoc.2017.04.045

[38] X. Vendrell, J. E. García, X. Bril, D. A. Ochoa, L. Mestres and G. Dezanneau, Improving the functional properties of $(\mathrm{K} 0.5 \mathrm{Na} 0.5) \mathrm{NbO} 3$ piezoceramics by acceptor doping, J. Eur. Ceram. Soc. 35 (2015) 125-130

[39] R.D. Shannon, Revised Effective Ionic Radii and Systematic Studies of Interatomie Distances in Halides and Chaleogenides, Acta Cryst A32 (1976) 751-767

[40] F. Rubio-Marcos, J. J. Romero, M. S. Martín-Gonzalez, J. F. Fernandez, Effect of stoichiometry and milling processes in the synthesis and the piezoelectric properties of modified KNN nanoparticles by solid state reaction, J. Eur. Ceram. Soc. 30 (2010) 2763-2771.

[41] Single Crystal and Powder Diffraction - Freely Available Crystallographic Software for Academia: http://www.ccp14.ac.uk/mirror/mirror.htm

[42] F. Rubio-Marcos, R. López-Juárez, R. E. Rojas-Hernandez, A. Del Campo, N. Razo-Pérez and J. F. Fernandez, Lead-free piezoceramics: Revealing the role of the rhombohedral-tetragonal phase coexistence in enhancement of the piezoelectric properties, ACS Appl. Mater. Interfaces 7 (2015) 23080-23088.

[43] O. Masson, Peakoc software, http://www.esrf.eu/computing/scientific/PEAKOC/MAIN.htm

[44] F. Rubio-Marcos, J.J. Romero, D.A. Ochoa, J.E. García, R. Perez and J.F. Fernández, Effects of poling process on KNNmodified piezoceramic properties, J. Am. Ceram. Soc. 93 (2010) 318-321.

[45] R. Zuo, J. Fu, and D. Lv, Phase transformation and tunable piezoelectric properties of lead-free $\left(\mathrm{Na0} .{ }_{52} \mathrm{~K}_{0.48 x} \mathrm{Li}_{\mathrm{x}}\right)\left(\mathrm{Nb} 1_{\mathrm{xy}} \mathrm{Sb}_{\mathrm{y}} \mathrm{Ta}_{\mathrm{x}}\right) \mathrm{O}_{3}$ system, J. Am. Ceram. Soc. 92 (2009) 283-285.

[46] R. Yu, H. Hojo, K. Oka, T. Watanuki, A. Machida, K. Shimizu, K. Nakano and M. Azuma, New PbTiO3-type giant tetragonal compound $\mathrm{Bi}_{2} \mathrm{ZnVO}_{6}$ and its stability under pressure, Chem. Mater. 27 (2015) 2012-2017.

[47] F. Rubio-Marcos, M.A. Bañares, J.J. Romero and J. F. Fernández, Correlation between the piezoelectric properties and the structure of lead-free KNN-modified ceramics studied by Raman spectroscopy, J. Raman Spectrosc. 42 (2011) 639-643.

[48] F. Rubio-Marcos, M.G. Navarro-Rojero, J.J. Romero, P. Marchet and J.F. Fernández, Piezoceramics properties as a function of the structure in the system $(\mathrm{K}, \mathrm{Na}, \mathrm{Li})(\mathrm{Nb}, \mathrm{Ta}, \mathrm{Sb}) \mathrm{O} 3$, IEEE Trans. Ultrason. Ferroelectr. Freq. Control 56 (2009) 1835-1842.

[49] R. Zuo, J Fu, G.Z. Yin, X.L. Li, J.Z. Jiang, Electric field induced phase instability in typical (Na,K)(Nb,Sb)O3-LiTaO3 ceramics near orthorhombic and tetragonal phase boundary, Appl. Phys. Lett. 101 (2012) 092906.

[50] J. Fu, R. Zuo, Y. Xu, J.-F. Li, M. Shi., Investigations of domain switching and lattice strains in (Na,K)NbO3-based leadfree ceramics across orthorhombic-tetragonal phase boundary, J. Eur. Ceram. Soc. 37 (2017) 975.

[51] B. Zhang, J. Wu, X. Cheng, X. Wang, D. Xiao, J. Zhu, X. Wang and X. Lou, Lead-free piezoelectrics based on potassiumsodium niobate with giant $\mathrm{d}_{33}$, ACS Appl. Mater. Interfaces 5 (2013) 7718-7725.

[52] B. Zhang, X. Wang, X. Cheng, J. Zhu, D. Xiao and Wu, Enhanced $d_{33}$ value in $(1-\mathrm{x})\left[\left(\mathrm{K}_{0.50} \mathrm{Na}_{0.50}\right) 0.97 \mathrm{Li}_{0.03} \mathrm{Nb}_{0.97} \mathrm{Sb}_{0.03} \mathrm{O}_{3}\right]-\mathrm{xBaZrO}_{3}$ lead-free ceramics with an orthorhombic-rhombohedral phase boundary, J. Alloys Compd. 581 (2013) 446-451.

[53] B. Noheda, D. E. Cox, G. Shirane, J.A. Gonzalo, L. E. Cross and S-E. Park, A monoclinic ferroelectric phase in the $\mathrm{Pb}\left(\mathrm{Zr}_{1-}\right.$ $\left.{ }_{x} \mathrm{Ti}_{\mathrm{x}}\right)_{\mathrm{O}}$ solid solution, Appl. Phys. Lett. 74 (1999) 2059.

[54] H.X. Fu and R.E. Cohen, Polarization rotation mechanism for ultrahigh electromechanical response in single-crystal piezoelectrics, Nature 403 (2000) 281-283.

[55] B. Noheda, D. E. Cox, G. Shirane, S.-E. Park, L.E. Cross and Z. Zhong, Polarization rotation via a monoclinic phase in the piezoelectric $92 \% \mathrm{PbZn}_{1 / 3} \mathrm{Nb}_{2 / 3} \mathrm{O}_{3}-8 \% \mathrm{PbTiO}_{3}$, Phys. Rev. Lett. 86 (2011) 3891-3894. 
This is the post-print (i.e. final draft post-refereeing) of the publication.

The final publication is available at Elsevier via http://dx.doi.org/ 10.1016/j.jeurceramsoc.2017.04.045

[56] R. Herbiet, U. Robels, H. Dederichs and G. Arlt, Domain wall and volume contributions to material properties of PZT ceramics, Ferroelectrics 98 (1989) 107-121.

[57] Z. Zhao, V. Buscaglia, M. Viviani, M.T. Buscaglia, L. Mitoseriu, A. Testino, M. Nygren, M. Johnsson and P. Nani, Grainsize effects on the ferroelectric behavior of dense nanocrystalline $\mathrm{BaTiO}_{3}$ ceramics, Phys. Rev. B 70 (2004) 024107.

[58] C.A. Randall, N. Kim, J.-P. Kucera, W.W. Cao and T. R. Shrout, Intrinsic and extrinsic size effects in fine-grained morphotropic-phase-boundary lead zirconate titanate ceramics, J. Am. Ceram. Soc. 81 (1998) 677-688.

[59] M. Muthuramalingam, D.E. Jain Ruth, M. Veera Gajendra Babu, N. Ponpandian, D. Mangalaraj and B. Sundarakannan, Isothermal grain growth and effect of grain size on piezoelectric constant of $\mathrm{Na}_{0.5} \mathrm{Bi}_{0.5} \mathrm{TiO}_{3}$ ceramics, Scr. Mater. 112 (2016) 58-61.

[60] X. Wang, T. Zheng, J. Wu, D. Xiao, J. Zhu, H. Wang, X. Wang, X. Lou and Y. Gu, Characteristics of giant piezoelectricity around the rhombohedral-tetragonal phase boundary in $(\mathrm{K}, \mathrm{Na}) \mathrm{NbO}_{3}$-based ceramics with different additives, J. Mater. Chem. A 3 (2015) 15951-15961.

[61] J. Y. Li, R. C. Rogan, E. Ustundag and K. Bhattacharya, Domain switching in polycrystalline ferroelectric ceramics, Nat. Mater. 4 (2005) 776-781 


\section{Supplementary Information}

\section{Understanding the Piezoelectric Properties in Potassium-Sodium Niobate- Based Lead-free Piezoceramics: Interrelationship between Intrinsic and Extrinsic Factors}

Fernando Rubio-Marcos ${ }^{\dagger, \xi, *}$, José F. Fernandez ${ }^{\dagger}$ Diego A. Ochoa", José E. Garcíall, Rocio E. Rojas-Hernandez ${ }^{\dagger}$, Miriam Castro $\neq$, Leandro Ramajo ${ }^{\neq,}$, ,

† Electroceramic Department, Instituto de Cerámica y Vidrio, CSIC, Kelsen 5, 28049, Madrid, Spain.

/Department of Physics, Universitat Politècnica de Catalunya - BarcelonaTech, Jordi Girona 1-3, 08034 Barcelona, Spain.

${ }^{\ddagger}$ Institute of Research in Materials Science and Technology (INTEMA) (CONICET - University of Mar del Plata), J. B. Justo 4302 (B7608FDQ) Mar del Plata, Argentina.

*Correspondence and requests for materials should be addressed to F.R.-M. (email: frmacos@icv.csic.es) and L. R. (email: 1ramajo@fi.mdp.edu.ar) 


\section{A. Relative volume fraction of crystallographic phases}

As described in the main manuscript, all samples present the polymorphic behavior, which is associated with the room temperature coexistence between a tetragonal symmetry $(T, \mathbf{P} 4 \mathrm{~mm})$ and an orthorhombic symmetry $(O, A m m 2)$. We calculate the relative volume fractions of the $T\left(V_{T}\right)$ and $\boldsymbol{O}\left(V_{O}\right)$ phases of the multiphase coexistence as: ${ }^{1-2}$

$$
\begin{aligned}
V_{T} & =\frac{\left[I_{(002)_{T}}+I_{(200)_{T}}\right]}{\left[I_{(002)_{T}}+I_{(200)_{T}}+I_{(022)_{O}}+I_{(200)_{O}}\right]} \\
V_{O} & =\frac{\left[I_{(022)_{O}}+I_{(200)_{O}}\right]}{\left[I_{(002)_{T}}+I_{(200)_{T}}+I_{(022)_{O}}+I_{(200)_{O}}\right]}
\end{aligned}
$$

where $\boldsymbol{I}_{(002) T}, \boldsymbol{I}_{(200) T}$, and $\boldsymbol{I}_{(022) \mathrm{O}}$, and $\boldsymbol{I}_{(200) \mathrm{O}}$ are the integrated intensities of the tetragonal (002) and (200) peaks, and orthorhombic (022) and (200) peaks, respectively. Hence, the composition dependences of $V_{T}$ and $V_{O}$ are given in Fig. S1, and the evolution of the $\mathbf{T} / \boldsymbol{O}$ ratio is summarized in the Table included in Fig. S1. As stated in the main manuscript, over the all compositional range $0.00 \leq x \leq 0.05$, the structural refinement results in a coexistence of phases at room temperature; i.e., a mixed $\boldsymbol{O}+\boldsymbol{T}$ phase. A detailed inspection of Fig. S1 reveals that $V_{T}$ and $V_{O}$ are dependent on the $\mathrm{Zr}^{4+}$ content; that is, $V_{T}$ first increases and then decreases as $\mathrm{x}$ increases, reaching a peak value of $\mathrm{V}_{\mathrm{T}} \sim 75 \%$ with a $\mathrm{T} / \mathrm{O}$ ratio close to 3 for $\mathrm{x}=$ 0.005 .

These results illustrate a clear pattern: stabilization of the $T$ phase into the polymorphic phase boundary $(\mathrm{O}+\mathrm{T}$ phase coexistence) at room temperature affords the best piezoelectric response (see Figs. 3 and 5 in the main manuscript). However, this fact is only one piece of this puzzle, which can be exclusively completed by understanding the interrelationship between the intrinsic and extrinsic effects of the system. 


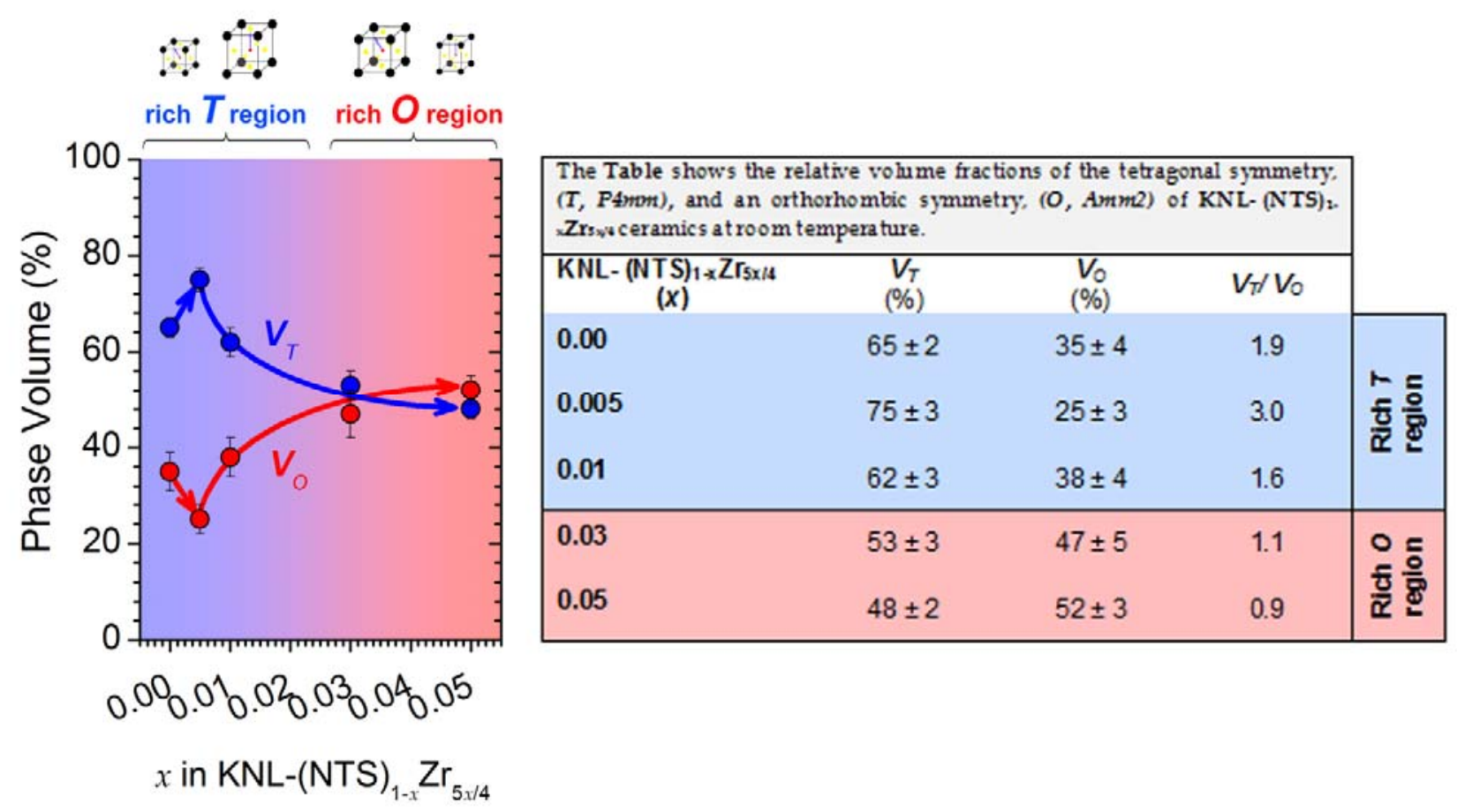

Figure S1 | Composition effect on the volume fraction of $T$ and $O$ phases. The error bars show the standard deviation of the relative volume fraction of $T$ and $O$ phases of each sample. The table summarizes the relative volume fractions and their ratios for each composition. 


\section{B. Domain switching and electric-field-induced lattice strain}

$\mathrm{X}$-ray diffraction (XRD) is a versatile technique for studying the average structural and crystallographic response to applied electric fields in piezoelectric materials. The ferroelastic domains reorientation can be quantified from the integrated intensities of degenerate reflections, such as the 002 and 200 tetragonal reflection, obtained from line profile analysis. The XRD data processing enables the quantification of the lattice strain and the extrinsic strain exerted by the sample, and provides insight into the correlation between the microstructure and the macroscopic strain. ${ }^{3}$ Following the procedure performed by Ochoa et al. ${ }^{3}$ the 002 and 200 degenerate reflections were fitted using line profile analysis. Assuming that the asymmetric nature of the peaks cannot be adequately fitted by using symmetric profile shape functions, only the symmetrical portion of the asymmetric peaks are fitted. This is accomplished by using the outer intensities of each respective peak (e.g. low $2 \theta$ side of the 002 reflection), and assuming that this half of the peak is equivalent to the symmetric portion of the other half of the peak. A symmetric Pearson VII profile function is used in the fitting. ${ }^{4}$ The absolute electric-field-induced lattice strain Ehkl (intrinsic contribution) is obtained from the shift in the peak position, whereas the relative percent of domain switching $\eta_{002}$ (extrinsic contribution) is obtained from the variation of the integrated intensities (or the areas) of the 002 and 200 peaks, as follows:

$$
\begin{aligned}
\eta_{002} & =\frac{\frac{N_{002}^{\text {poled }}}{N_{002}^{\text {unpoled }}}}{\frac{N_{002}^{\text {pled }}}{N_{002}^{\text {unoled }}}+2\left(\frac{N_{200}^{\text {poled }}}{N_{200}^{\text {unpoled }}}\right)}-\frac{1}{3} \\
\varepsilon_{h k l} & =\left|\frac{d_{h k l}^{\text {poled }}-d_{h k l}^{\text {unpoled }}}{d_{h k l}^{\text {unpoled }}}\right|
\end{aligned}
$$

where $N$ and $d$ are the area and the $d$-spacing of the corresponding fitted peak. The $d$-spacing is directly obtained from the $2 \theta$ values, taking into account the wavelength of the applied X-rays. Table S1 
summarizes the fit results that are used to calculate the domain switching $\left(\eta_{002}\right)$ and the lattice strain contributions ( $\varepsilon_{002}$ and $\left.\varepsilon_{200}\right)$. The compositional dependence of $\eta_{002}$ and $\varepsilon_{002}$ are shown in Figs. $\mathbf{5 b}$ and $\mathbf{5 c}$ in the main manuscript, respectively, and reveal the evolution of these contribution to the poling process. The compositional-dependent $\varepsilon_{200}$ (not shown) exhibits a similar trend to that observed for $\varepsilon_{002}$ confirming the evolution of the intrinsic contribution with the $\mathrm{Zr}^{4+}$ content in $\mathrm{KNL}-(\mathrm{NTS})_{1-\mathrm{x}} \mathrm{Zr}_{5 \times / 4}$ system. In a similar approach, the percentage of non- $180^{\circ}$ domains reorientation $(R)$ can be calculated from the data in Table S1, as follow: 5

$$
R=\frac{\left(\frac{N_{200}}{N_{002}}\right)^{\text {unpoled }}-\left(\frac{N_{200}}{N_{002}}\right)^{\text {poled }}}{\left(\frac{N_{200}}{N_{002}}\right)^{\text {unpoled }}+2\left(\frac{N_{200}}{N_{002}}\right)^{\text {poled }}}
$$

The calculation result shows a compositional dependence of $R$ similar to that observed for $\eta_{002}$, thereby validating the dependence of the extrinsic contribution with the $\mathrm{Zr}^{4+}$ content.

Table S1 | Results obtained from the peak fitting analysis of the 002 and 200 reflections for all unpoled and poled samples of the KNL-(NTS) $)_{1-x} \mathrm{Zr}_{5 \times / 4}$ system. $N$ represents the peak area whereas $2 \theta$ denotes the position of the peak maximum. All values are given with their standard deviations.

\begin{tabular}{|c|c|c|c|c|c|}
\hline \multicolumn{6}{|c|}{ unpoled state } \\
\hline$x$ & 0.00 & 0.005 & 0.01 & 0.03 & 0.05 \\
\hline$N_{002}$ & $14 \pm 3$ & $12 \pm 2$ & $15 \pm 1$ & $24 \pm 1$ & $32 \pm 3$ \\
\hline$N_{200}$ & $16.4 \pm 0.8$ & $16.0 \pm 0.8$ & $19.4 \pm 0.8$ & $21.6 \pm 0.8$ & $18 \pm 4$ \\
\hline $2 \theta_{002}$ & $45.30 \pm 0.01$ & $45.28 \pm 0.01$ & $45.36 \pm 0.01$ & $45.50 \pm 0.01$ & $45.6 \pm 0.02$ \\
\hline $2 \theta_{200}$ & $45.96 \pm 0.01$ & $45.95 \pm 0.01$ & $45.91 \pm 0.01$ & $45.84 \pm 0.01$ & $45.81 \pm 0.02$ \\
\hline \multicolumn{6}{|c|}{ poled state } \\
\hline $\mathbf{x}$ & 0.00 & 0.005 & 0.01 & 0.03 & 0.05 \\
\hline$N_{002}$ & $20.2 \pm 0.8$ & $20.1 \pm 0.8$ & $25 \pm 1$ & $43 \pm 1$ & $43 \pm 3$ \\
\hline$N_{200}$ & $7.3 \pm 0.3$ & $10 \pm 2$ & $15 \pm 1$ & $17.8 \pm 0.8$ & $16 \pm 4$ \\
\hline $2 \theta_{002}$ & $45.34 \pm 0.01$ & $45.34 \pm 0.01$ & $45.39 \pm 0.01$ & $45.52 \pm 0.01$ & $45.62 \pm 0.02$ \\
\hline $2 \theta_{200}$ & $46.02 \pm 0.01$ & $46.02 \pm 0.01$ & $45.94 \pm 0.01$ & $45.88 \pm 0.01$ & $45.84 \pm 0.02$ \\
\hline
\end{tabular}




\section{Temperature dependence of dielectric permittivity}

The temperature dependence of dielectric constant of KNL-(NTS) $)_{1-x} \mathrm{Zr}_{5 \times / 4}$ ceramics measured at different frequency range is shown in Figure S2a (The reader can find more information about the temperature dependence of the dielectric permittivity $\varepsilon_{r}$ and the transition temperatures of the $K N L-(N T S)_{1-x} Z_{5 x / 4}$ ceramics in Figure 2 of the main manuscript).

Fig. S2a shows the temperature dependence of the real dielectric permittivity of KNL-(NTS $)_{1-x} \mathrm{Zr}_{5 \times / 4}$ ceramics in the frequency range from $1 \mathrm{kHz}$ to $500 \mathrm{kHz}$. For compositions with low $\mathrm{Zr}^{4+}$ content $(0 \leq \mathrm{x}$ $\leq 0.01$ ), the dielectric permittivity displays a sharp peak, suggesting that these ceramics are normal ferroelectrics. However, for compositions with higher $\mathrm{Zr}^{4+}$ content $(x \geq 0.03)$, the $\varepsilon_{r}-T$ plot broadens, showing the general features of a diffuse phase transition (see insert of Fig. S2a). To verify such behavior, the diffuseness of the phase transition is determined from a modified Curie-Weiss law:

$$
\frac{1}{\varepsilon_{r}}-\frac{1}{\varepsilon_{m}}=\frac{\left(T-T_{m}\right)^{\gamma}}{C}
$$

where $\varepsilon_{\mathrm{m}}$ is the $\varepsilon_{\mathrm{r}}$ maximum, $T_{\mathrm{m}}$ is the temperature at which this maximum occurs, $C$ is the Curie-Weiss constant, and the parameter $\gamma$ indicates the character of the phase transition. Thus, $\gamma=2$ corresponds to a complete diffuse phase transition, while $\gamma=1$ corresponds to a normal ferroelectric-paraelectric phase transition. 6,7 In general, $\gamma$ takes a value between these limits $(1<\gamma<2)$, indicating an "incomplete" diffuse phase transition. Figure $2 \mathrm{Sb}$ shows the plots of $\ln \left(1 / \varepsilon^{\prime}-1 / \varepsilon_{\mathrm{m}}\right)$ versus $\ln \left(\mathrm{T}-\mathrm{T}_{\mathrm{m}}\right)$ for KNL-(NTS) $)_{1-\mathrm{x}} \mathrm{Zr}_{5 \times / 4}$ ceramics with different $\mathrm{Zr}^{4+}$ contents. All the samples exhibit a linear relationship. The $\gamma$ values are calculated by least-squares fitting of the experimental data to the equation (6). As shown in Figure S2c, the $\gamma$ value quickly decreases and then dramatically increases as the $x$ content increases, reaching a minimum value for $x=0.005$. The results indicate that the KNL-(NTS) $)_{-x} Z_{5 x / 4}$ system evolves from a normal-like ferroelectric phase transition toward a diffuse phase transition. The origin of this behavior can be related to chemical heterogeneities. These heterogeneities are characteristics of polymorphism 
and generally appear as polar nanoregions (which are typical in relaxor systems) or when phase diffusions are present. 8,9

As mentioned above and in the main manuscript, doping effects on ceramics are also reflected in the $\mathrm{T}_{\mathrm{C}}$ transition. In $\mathrm{KNL}-(\mathrm{NTS})_{1-\mathrm{x}} \mathrm{Zr}_{5 \times / 4}$ system, $\mathrm{Nb}^{5+}, \mathrm{Ta}^{5+}, \mathrm{Sb}^{5+}$ and $\mathrm{Zr}^{4+}$ occupy the $\mathrm{B}$ sites of $\mathrm{ABO}_{3}$ perovskite structure, but $\mathrm{Zr}^{4+}$ possesses different valence and ionic radii than $\mathrm{Nb}^{5+}, \mathrm{Ta}^{5+}, \mathrm{Sb}^{5+}$, which result in the formation of the local electric fields owing to the local charge imbalance, and the local elastic fields due to local structure distortions.
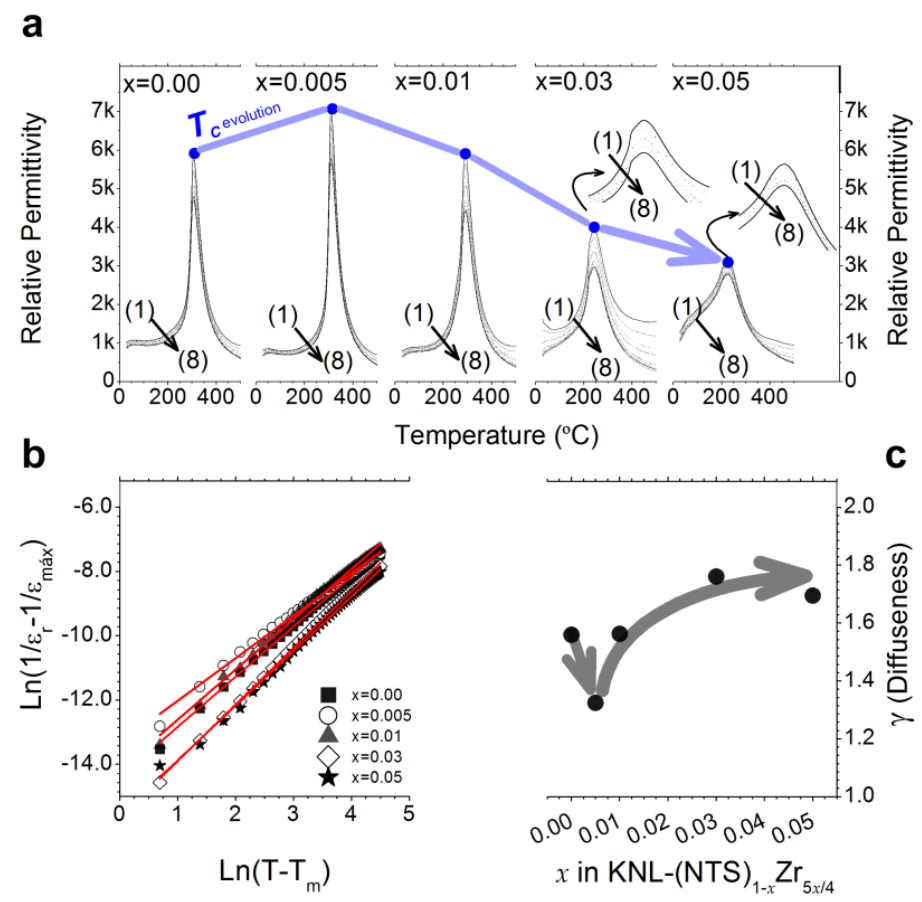

Figure S2 | (a) Real permittivity $\left(\varepsilon_{\mathrm{r}}\right)$ vs. temperature of $\mathrm{KNL}-(\mathrm{NTS})_{1-\mathrm{x}} \mathrm{Zr}_{5 \mathrm{x} / 4}$ sintered ceramics as a function of frequency. The insets of the compositions with $x \geq 0.03$ show broad dielectric peaks around the Curie temperature $\left(\mathrm{T}_{\mathrm{C}}\right)$, which implies the characteristic of diffuse phase transition. The frequency range represented in Fig. S2a are the following: (1) 1 kHz; (2) 2 kHz; (3) $5 \mathrm{kHz}$; (4) $10 \mathrm{kHz}$; (5) $50 \mathrm{kHz}$; (6) $100 \mathrm{kHz}$; (7) $200 \mathrm{kHz}$; and (8) $500 \mathrm{kHz}$. Arrows indicate increasing measurement frequency from $1 \mathrm{kHz}$ to $500 \mathrm{kHz}$. (b) Plots corresponding to the modified Curie-Weiss law for the KNL-(NTS)1-x Zr $5 x / 4$ ceramics. The symbols denote experimental data, while the red lines correspond to the least-squares fitting of the modified Curie-Weiss law. (c) Diffuseness, $y$, of the ceramics as a function of $x$. 


\section{Supplementary References}

(1) Ge, W.; Li, J.; Viehland, D.; Chang,Y.; Messing, G.L. Electric-Field-Dependent Phase Volume Fractions and Enhanced Piezoelectricity Near the Polymorphic Phase Boundary of $\left(\mathrm{K}_{0.5} \mathrm{Na}_{0.5}\right)_{1-\mathrm{x}} \mathrm{Li}_{\mathrm{x}} \mathrm{NbO}_{3}$ Textured Ceramics Phys. Rev. B 2011, 83, 224110.

(2) Rubio-Marcos, F.; López-Juárez, R.; Rojas-Hernandez, R. E.; Del Campo, A.; Razo-Pérez, N.; Fernandez, J. F. Lead-Free Piezoceramics: Revealing the Role of the Rhombohedral-Tetragonal Phase Coexistence in Enhancement of the PiezoelectricProperties ACS Appl. Mater. Interfaces 2015, 7 (41), 23080-23088.

(3) Ochoa, D.A.; Esteves, G.; Iamsasri, T.; Rubio-Marcos, F.; Fernández, J.F.; García, J.E.; Jones, J.J. Extensive Domain Wall Contribution to Strain in a $(\mathrm{K}, \mathrm{Na}) \mathrm{NbO}_{3}$-Based Lead-Free Piezoceramics Quantified from High Energy X-Ray Diffraction J. Eur. Ceram. Soc. 2016, 36, 2489-2494.

(4) Daniels, J.E.; Jones, J.L.; Finlayson, T.R. Characterization of Domain Structures from Diffraction Profiles in Tetragonal Ferroelastic Ceramics J. Phys. D. Appl. Phys. 2006, 39, 5294-5299.

(5) Zhang, X.; Lei, C.; Chen, K. Ferroelectric $90^{\circ}$ Domain Evaluation in Tetragonal $\mathrm{Pb}\left(\mathrm{Mg}_{1 / 3} \mathrm{Nb}_{2 / 3}\right) \mathrm{O}_{3}-\mathrm{PbTiO}_{3}$ ceramics J. Am. Ceram. Soc. 2005, 88, 335-338.

(6) Uchino, K.; Nomura, S. Critical Exponents of the Dielectric Constants in Diffused-Phase-Transition Crystals Ferroelectr. Lett. Sect. 1982, 44, 55-61.

(7) Smolenskii, G.A. Physical phenomena in ferroelectrics with diffused phase transitions Phys. Soc. Jpn. (Suppl.) 1970, 28, 2637.

(8) Ramajo, L.; Castro, M.; del Campo, A.; Fernandez, J.F.; Rubio-Marcos, F. Revealing the Role of Cationic Displacement in Potassium-Sodium Niobate Lead-Free Piezoceramics by Adding W6+ Ions J. Mater. Chem. C 2015, 3, 4168-4178.

(9) Lv, X.; Wu, J.; Yang, S.; Xiao, D.; Zhu, J. Identification of Phase Boundaries and Electrical Properties in Ternary PotassiumSodium Niobate-Based Ceramics ACS Appl. Mater. Interfaces 2016, 8, 18943-18953. 